\title{
The Influence of Professionally Oriented Physical Training Means on the Operator's Physical Ability Level
}

\author{
Volodymyr Klymovych', Artur Oderov', Serhii Romanchuk', Mukola Korchagin ${ }^{2}$, Andrii Chernozub ${ }^{3}$, Oleh \\ Olkhovyi ${ }^{3}$ and Vitalii Zolochevskyi ${ }^{4}$
}

${ }^{1}$ National Academy of the Army, Department of Physical Education, Special Physical Training and Sports, Lviv, Ukraine, ${ }^{2}$ Military Institute of Armored Forces of National Technical University Kharkiv Polytechnic Institute, Department of Physical Education, Special Physical Training and Sports, Kharkiv, Ukraine, ${ }^{3}$ Petro Mohyla Black Sea National University, Faculty of Physical Education and Sports, Mykolaiv, Ukraine, ${ }^{4}$ Kozhedub Air Force University, Department of Physical Education, Special Physical Training and Sports, Kharkiv, Ukraine

\section{Abstract}

To study the effect of professionally applied vocationally-directed physical training on the level of professionally important physical qualities of operators, a three-year experiment was conducted to implement a programme of special (professionally-directed) physical training in the daily professional activity of servicemen-control systems-operators. The analysis of scientific and methodological literature and the domestic experience of organizing vocationally applied physical training supports the claim that a large number of fundamental and applied scientific research studies are devoted to the problem of formation of professionally important physical qualities, in which the current directions and tendencies of the orientation of physical education professions and culture are presented. The use of an experimental programme, based on the means of vocationally directed physical training, enabled the statistically significant improvement of the level of development of professionally important physical qualities of experimental group (EG) operators in relation to the control group (CG): aerobic endurance by $2.2 \%(p<0.05)$, agility by $3.7 \%(p<0.05)$, strength endurance by $9.4 \%(p<0.05)$, static endurance of back and neck muscles by $13.2 \%(p<0.05)$, general static endurance by $11.1 \%(p<0.05)$. Studies show that through the purposeful use of exercise, it is possible to form a certain level of development of professionally important physical qualities, in order to ensure constant physical readiness to perform professional tasks.
\end{abstract}

Keywords: physical training, physical abilities, military operator, automated systems, ability level

\section{Introduction}

Applied professional physical training of operator specialists is done for the preparation of military personal for concrete future military activity (Olkhovyi, 2015). It promotes the development of physical and mental abilities that are necessary for their future profession, and for forming the motor skills, according to the profile of future military activity (Rayevsky \& Kanisevsky, 2010). Physical readiness, performance optimization, and injury prevention are critical to the military profession and specifically to the individual operator (Klymovych \&
Olkhovyi, 2016). Modern ideas about physical activity extend this statement so that it includes the improvement of physical condition, the preservation of health, and the lengthening of professional longevity.

According to Kamaiev et al. (2018), the effectiveness and reliability of the operator profile specialists are closely related to the development level of professionally important physical qualities. Analysis of the most recent research and publications shows that military operators are specially trained to perform their tasks on the battlefield (Korchagin, Kurbakova,

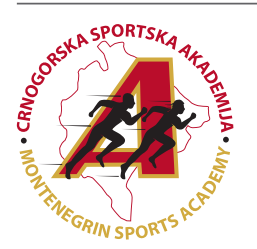

Correspondence:

V.B. Klymovych

National Academy of the Army, Department of Physical Education, Special Physical Training and Sports, Heroyiv Maydanu, 79012 Lviv, Ukraine

E-mail: klimovichvolodymyr@gmail.com 
\& Olkhovyi, 2017).

The problem of the development and improvement of special (professionally important) physical and physiological qualities of future specialists in the modern professional education system is solved by professionally applied physical preparation (Klymovych, Olkhovyi, \& Romanchuk, 2016). If general physical training provides readiness for work in general, professionally oriented physical training is aimed at preparding military personal for a specific professional activity (Rolyuk et al., 2016).

The problem of the development and improvement of professionally important physical abilities is relevant not only at the stage of professional education, but also at the stage of adaptation to the conditions of professional activity (outside the educational institution), the stage of formation, and the direct professional activity of specialists (Bolotin, Bakayev, \& Vazhenin, 2016). Regarding the continuity of the physical education process of a person during his lifetime and the constantly changing negative health-affecting factors of professionals, it is advisable to combine the subsystems of professional-applied physical training and culture in a professional-oriented physical training system. The concept of such training of Ukrainian higher military educational institution graduates was proposed by Finogenov (2015). Logically, the proposed model of professional-oriented physical training of military personnel may be adapted to the requirements of various specialities' activity. The issues of professionally important physical abilities development, improvement and maintenance at the optimum level should be solved throughout the whole period of specialist's professional activity (Kruszewski et al., 2017).

During the previous research study, conducted on the base of Ukrainian Air Forces (Oderov et al., 2017), it was determined that the professional-important physical abilities of this category of operators were: static endurance of the back and neck muscles, static endurance of "muscle of the press" exercise, aerobic endurance, power endurance and agility. A block-periodization model was suggested for the Ukrainian Air Force automatic system personnel while managing operational duty schedules. The benefits of the block-periodization model are in the short cycles (microcycles), allowing concentration on the development of important physical abilities by professionally oriented physical training means.

The purpose of the article is to study the influence of professionally oriented means of physical education on the level of professionally important physical abilities of military operators of automated systems.

\section{Methods}

Pedagogical methods of investigation, testing of physical abilities level and statistical analysis of the results were used in the study.

Eighty-six (86) military automatic system operators (22-30 years old) from the Ukrainian Air Forces were involved in the research. All operators were informed about the experiment and gave their assent. All of them were clinically healthy and had no recent history of infectious disease, asthma, or cardio-respiratory disorders. They were divided into two equal groups (control and experimental), which were tested before, during, and after the implementation of author's special physical training programme. The experimental group (EG) performed the block-periodization model training, whereas the control group (CG) continued performing the current training programme. The total duration of the study was three years.

A battery of tests was used for assessment of professionally important physical abilities level.

1. $3 \mathrm{~km}$ running (for aerobic endurance assessment);

2. Complex power test (for power endurance assessment);

3. Complex agility test (for agility assessment);

4. Keeping horizontal back position (for back and neck static endurance assessment);

5. L-sit on parallel bars with knees bent (for assessment of the static endurance of abdominal muscles).

The pedagogical experiment was used to determine the influence of means of professional-applied physical training on physical development and the level of development of professionally important physical qualities of operators. A control $(n=43)$ and an experimental $(n=43)$ group of operators of the same level of professional preparedness were formed. During the experiment, representatives of the experimental group, trained for the author's programme of professional-oriented physical training, performed professional duties in the usual mode.

Pedagogical testing was conducted to assess the level of physical fitness of the operators by means of control exercises: running at $3 \mathrm{~km}$, complex exercise on dexterity, complex exercise, maintaining straight legs on gym equipment, static holding of the horizontal back position.

Methods of mathematical processing of the obtained results were used to characterize the groups studied and to identify the difference between the groups among the groups with the help of functions (arithmetic mean in groups - mean square deviations - $\sigma$, errors of arithmetic mean - $m$ ). The probability of differences on one sign before and after the experiment and in two different groups was evaluated according to the t-test.

The following tools were used to build the author's programme of special (professional-oriented) physical training: isotonic general development exercises, isometric exercises for the muscles of the back, neck and the press, cyclic exercises of low and moderate intensity, sets of physical culture pauses, exercises for relaxation and muscle stretching, sports and games, and hydrothermal procedures.

To study the aspect of the influence of special physical training on the level of professionally important physical qualities of operators, a three-year experiment was conducted to implement a programme of special (professional-oriented) physical training into the daily activities of servicemen-operators.

\section{Results}

The effectiveness of the formation of indicators of professionally important physical qualities of operators is shown in Table 1 (where EG is an experimental group using the author's programme of professionally applied vocational-directed physical training, performed professional duties in the normal mode and CG is the control group, which engaged in the usual programme).

A comparative analysis of the level of development of endurance (average arithmetic run time running $3 \mathrm{~km}$ ) from the operators showed that an increase in this indicator from the representatives of the CG in relation to representatives of the EG was observed during the experiment, and this difference is $2.2 \%$ at $\mathrm{t}=2.12$.

A comparative analysis of the level of development of strength endurance (average arithmetic number of repetitions of a complex exercise) showed a statistically significantly bet- 
Table 1. Research results indicators of professionally important physical qualities of operators

\begin{tabular}{|c|c|c|c|c|c|}
\hline $\begin{array}{c}\text { Period of } \\
\text { determination }\end{array}$ & $\begin{array}{c}E G(n=43) \\
M \pm S D\end{array}$ & $\begin{array}{c}C G(n=43) \\
M \pm S D\end{array}$ & $\begin{array}{c}\text { Difference } \\
(\%)\end{array}$ & T-test & Sig. \\
\hline \multicolumn{6}{|c|}{ Endurance - Running 3 km (s) } \\
\hline Before experiment & $835.26 \pm 5.61$ & $836.51 \pm 5.79$ & 0.2 & 0.16 & $\mathrm{p}>0.05$ \\
\hline After experiment & $838.09 \pm 5.60$ & $856.53 \pm 6.68$ & 2.2 & 2.12 & $p<0.05$ \\
\hline \multicolumn{6}{|c|}{ Complex force exercises (s) } \\
\hline Before experiment & $39.95 \pm 1.38$ & $39.88 \pm 1.21$ & 0.2 & 0.04 & $\mathrm{p}>0.05$ \\
\hline After experiment & $41.74 \pm 1.29$ & $38.14 \pm 1.11$ & 9.4 & 2.11 & $\mathrm{p}<0.05$ \\
\hline \multicolumn{6}{|c|}{ Dexterity - Comprehensive exercise on dexterity (s) } \\
\hline Before experiment & $11.33 \pm 0.11$ & $11.36 \pm 0.12$ & 0.3 & 0.21 & $\mathrm{p}>0.05$ \\
\hline After experiment & $11.14 \pm 0.10$ & $11.57 \pm 0.12$ & 3.7 & 2.82 & $p<0.05$ \\
\hline \multicolumn{6}{|c|}{ angle on gymnastic bars (s) } \\
\hline Before experiment & $39.28 \pm 2.08$ & $38.95 \pm 1.46$ & 0.8 & 0.13 & $\mathrm{p}>0.05$ \\
\hline After experiment & $41.49 \pm 1.54$ & $37.33 \pm 1.25$ & 11.1 & 2.11 & $p<0.05$ \\
\hline \multicolumn{6}{|c|}{ Hold the body in a horizontal position (s) } \\
\hline Before experiment & $76.79 \pm 3.28$ & $76.88 \pm 2.79$ & 0.1 & 0.02 & $\mathrm{p}>0.05$ \\
\hline After experiment & $84.95 \pm 3.31$ & $75.05 \pm 2.86$ & 13.2 & 2.26 & $p<0.05$ \\
\hline
\end{tabular}

ter result of EG operators in relation to representatives of CG at $9.4 \%$ at $\mathrm{t}=2.11$.

The results of the evaluation of agility in EG operators after the experiment are statistically significantly different from the results of this indicator for the representatives of the CG; the average arithmetic mean of the time of execution of the exercise on agility was lower by $3.7 \%$ at $\mathrm{t}=2.82$.

Similarly, after the third year of the pedagogical experiment, the difference between the mean arithmetic mean of the exercise time on the static endurance of the muscles of the press and the static endurance of the muscles of the back and neck in the two groups was statistically significant: $11.1 \%$ at $\mathrm{t}=2.11$, respectively and by $13.2 \%$ at $\mathrm{t}=2.26$.

\section{Discussion}

To confirm the influence of means of professionally directed physical training on the level of professionally important physical qualities of specialists during the three years of using the author's programme, a study of the dynamics of the level of development of physical qualities of representatives of two groups of operators of automated control systems (Figure 1, 2 and 3) was conducted.
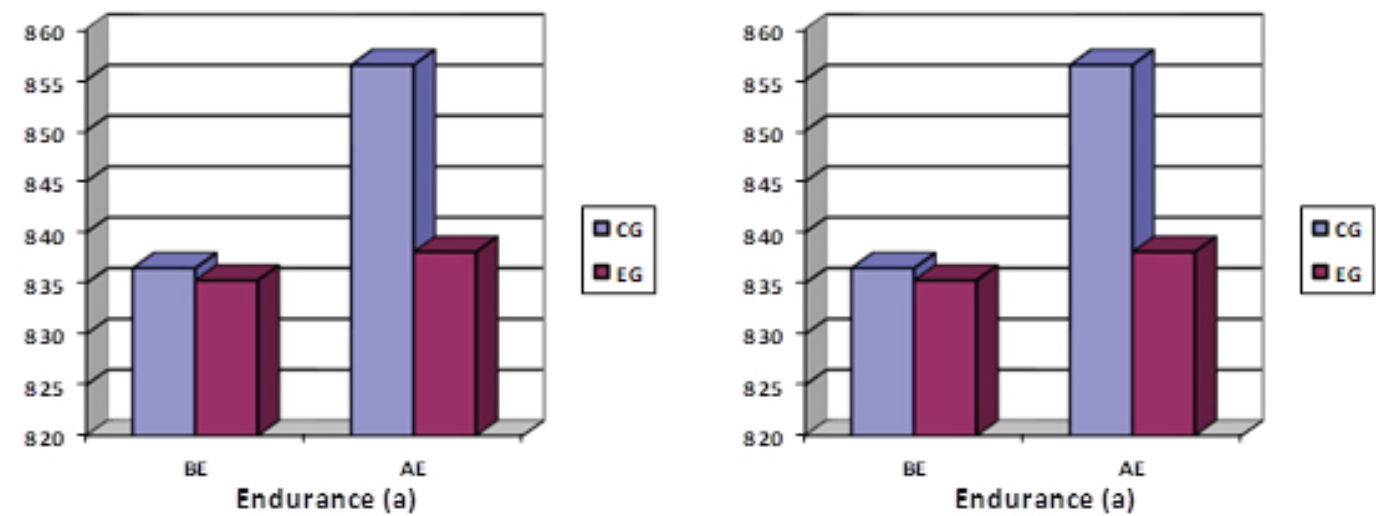

Figure 1. Dynamics of the level of development of aerobic endurance and strength endurance during the experiment

An analysis of the dynamics of the level of development of professionally important physical qualities of the CG operators stated that during three years of the experiment, as a result of aging of the body, statistically significantly deteriorated: aerobic endurance by $2.4 \%$ at $\mathrm{p}<0.01$ (Figure $1 \mathrm{a}$ ), strength endurance by $4.4 \%$ at $\mathrm{p}<0.001$ (Figure $1 \mathrm{~b}$ ). The level of development of aerobic endurance of representatives of EG for three years of the experiment has not undergone statistically significant changes (Figure 1a). Instead, the power endurance of the operators of EG for three years of the experiment has statistically significantly improved by $4.5 \%$ at $\mathrm{p}<0.001$ (Figure $1 \mathrm{~b}$ ).

The dynamics of the level of agility of operators (Figure 2) in the three years of the experiment showed that the agility of the representatives of the CG statistically significantly deteriorated by $1.5 \%$ at $\mathrm{p}<0.01$ (Figure 2), but the physical quality improved by EG operators by $1.9 \%$ at $\mathrm{p}<0.001$. 


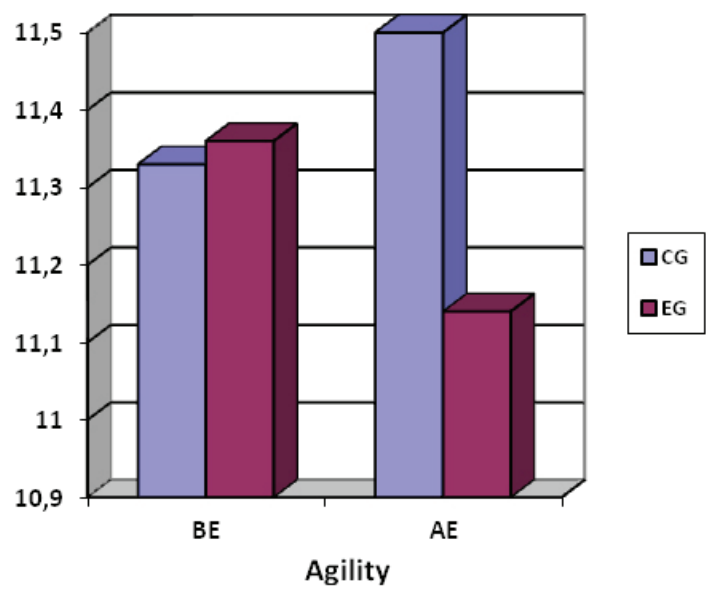

Figure 2.Dynamics of the level of development of agility during the experiment

The results of determining the static endurance of the muscles of the press, back, and neck of the CG operators indicate that these physical qualities have not undergone statistically significant changes (Figure 3). However, in the EG operators, the static endurance of the muscles of the press statistically significantly improved by $3.8 \%$ at $\mathrm{p}<0.001$ (Figure $3 \mathrm{a}$ ), while the static endurance of the muscles of the back and neck was $7.5 \%$ at $\mathrm{p}<0.001$ (Figure $3 \mathrm{~b}$ ).

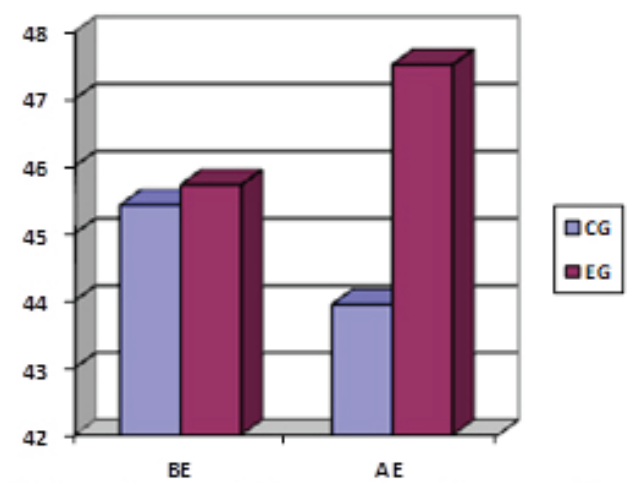

Static endurance of the muscles of the press (a)

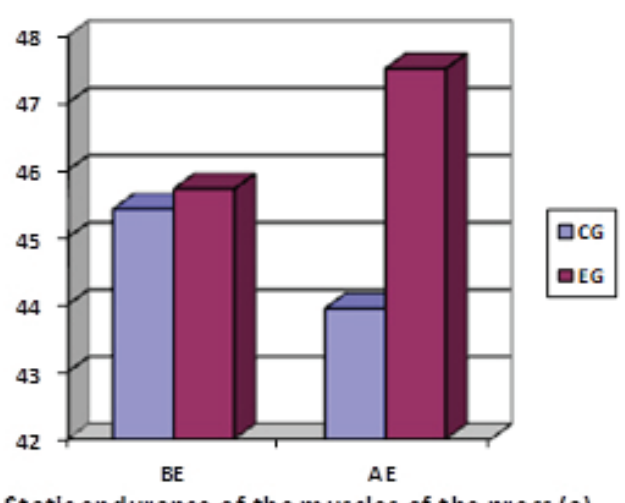

Static endurance of the muscles of the press (a)

Figure 3. Dynamics of the level of development of static endurance of the muscles of the press, back and neck during the experiment

The use of an experimental programme based on the means of professional-directed physical training enabled statistically significant improvements of the level of development of professional-important physical qualities of EG operators in relation to CG: aerobic endurance at $2.2 \%(\mathrm{p}<0.05)$, agility at $3.7 \%(\mathrm{p}<0.05)$, strength endurance at $9.4 \%(\mathrm{p}<0.05)$, static endurance of the back and neck muscles by $13.2 \%(\mathrm{p}<0.05)$, static endurance $m$ Pressure of the press at $11.1 \%(\mathrm{p}<0.05)$.

\section{Acknowledgements}

There are no acknowledgements.

\section{Conflict of Interest}

The authors declare that there are no conflicts of interest.

Received: 30 May 2019 | Accepted: 02 August 2019 | Published: 01 February 2020

\section{References}

Bolotin, A., Bakayev, V., \& Vazhenin, S. (2016). Pedagogical model for developing skills required by cadets of higher education institutions of the Aerospace Forces to organize their kettlebell self-training. Journal of Physical Education and Sport, 16(1), 177-186. doi:10.7752/ jpes.2016.01028

Finogenov, Yu.S. (2015). Methodical recommendations to organization of physical training in a special period: NUDU.

Kamaiev, O.I., Hunchenko, V.A., Mulyk, K.V., Hradusov, V.A., Homanyuk, S.V.,
Studies show that with the purposeful use of physical exercises it is possible to form a certain level of development of professionally important physical qualities so as to provide constant physical readiness for performing professional tasks.

In the future, we plan to direct research to determine the impact of professional-oriented physical training on the level of physical development of operators of automated control systems.

Mishyn, M.V., Martynenko, O.M., \& Shuryaev, V.P. (2018). Optimization of special physical training of cadets in the specialty «Arms and Military Equipment» on performing professional military-technical standards. Journal of Physical Education and Sport, 18(Supplement issue 4), 18081810. doi:10.7752/jpes.2018.s4264

Klymovych, V., Olkhovyi, O., \& Romanchuk, S. (2016). Adoption of youth`s bodies to educational conditions in higher educational institutions. Journal of Physical Education and Sport, 3(1), 620-622.

Klymovych, V. \& Olkhovyi, O. (2016). Influence on the dynamics of psychophysiological qualities. Actual scientific research in the modern world: Collection of scientific works XIV International (49-53).

Korchagin, M., Kurbakova, S., \& Olkhovyi, O. (2017). Dependence of the success of professional activity of servicemen-operators on the level of psychophysiological qualities. Sports Gazette of Prydniprovia, 5(3), 65-68.

Kruszewski, M., Kruszewski, A., Kuzmicki, S., Korczak, R., Tabecki, R., Landowski, K., \& Sitek, P. (2017).The effectiveness of kettlebell exercises in the aspects of special efficiency training in American football. Baltic 
Journal of Health and Physical Activity, 9(3), 53-62.

Olkhovyi, O.M. (2015). Theory and methodology of scientific research in physical education and sport. KSAPC, 1(2), 143 .

Oderov, A., Romanchuk, S., Fedak, S., Kuznetsov, M., Petruk, A., DunetsLesko, A., Lesko, O \& Olkhovyi, O. (2017). Innovative approaches for evaluating physical fitness of servicemen in the system of professional training. Journal of Physical Education and Sport, 17(Supplement issue 1) 23-27. doi:10.7752/jpes.2017.s1004
Rayevsky, R.T., \& Kanisevsky, S.M. (2010). Professional-Applied Physical Training of Students of Higher Educational Institutions. Science and Technology, 4(1), 378-380.

Rolyuk, A., Romanchuk, S., Romanchuk, V., Boyarchuk, A., Kyrpenko, V., Afonin, V., \& Orest, L. (2016). Research on the organism response of reconnaissance officers on the specific load of military exercises. Journal of Physical Education and Sport, 16(1), 132-135. https://doi.org/10.7752/ jpes.2016.01022 